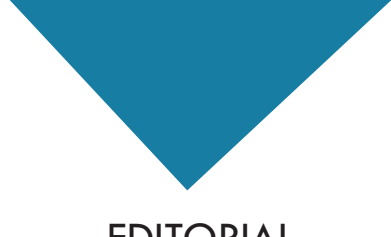

EDITORIAL

\title{
USO DO FIO DENTAL: HÁBITO INDISPENSÁVEL DE HIGIENE BUCAL
}

\author{
Sylvia Maria Correia Todescan*, Urbino da Rocha Tunes**
}

\begin{abstract}
Autora para correspondência: Sylvia Maria Correia Todescan - todescan@cc.umanitoba.ca
* Especialista, Mestre e Doutora em Periodontia USP - Bauru; Pós-doutorado Universidade de Toronto (Canada), Professora Associada do Curso de Odontologia da Universidade de Manitoba (Canada), Fellow in Periodontology Royal College of Dentist of Canada, Membro do Conselho Editorial da Revista Bahiana de Odontologia

** Doutor em Imunologia e Mestrado em Odontologia (UFBA). Especialista em Periodontia Social pela University of Illinois at Chicago (UIC/USA). Professor Titular da área de Periodontia do Curso de Odontologia da Escola Bahiana de Medicina e Saúde Pública (EBMSP); Coordenador do Curso de Graduação em Odontologia da EBMSP e Coordenador do Programa de Pós-graduação stricto-sensu (Mestrado) em Odontologia da EBMSP. Editor científico da Revista Bahiana de Odontologia
\end{abstract}

No mês passado um relatório da Associated Press disseminou que a evidência científica do uso do fio dental era fraca, não confiável e de baixa qualidade'. No mundo inteiro foi discutido calorosamente se os pacientes deveriam utilizar ou não o fio dental. Os orgãos de classe em cada país se manifestaram defendendo o uso. Esta discussão gerou um aumento de $600 \%$ na busca do Google relacionada ao tópico. A página da Academia Americana de Periodontia (AAP) registrou um aumento de $78.5 \%$ no número de acessos para localizar um periodontista. A resposta da AAP foi vista, lida e ouvida mais de 1.9 bilhões de vezes na televisão, rádio, imprensa escrita e web.

O uso do fio dental não é recente. $O$ dentista Levi Spear Parmly inventou o fio dental no início do século XIX. A primeira patente foi emitida em 1874, e o uso do fio dental começou a ser recomendado vastamente por dentistas da época. A Associação Americana de Odontologia (ADA) tem promovido a utilização do fio dental desde 1908. O Guia de Dieta Americano 2015-2020, publicado em 2016 , não inclui o uso do fio dental, pois não existe evidência científica validando a prática. A revisão de literatura Cochrane ${ }^{2}$ já evidenciava que muitos estudos abordando o uso do fio dental não tinham evidência cientifíca comprovada.

Considerando os níveis de evidência científica, o uso do fio dental seria categorizado como de baixa evidência e não seria recomendado. Os estudos publicados não são longitudinais, a metodologia tem design comprometido, com amostra reduzida, métodos de avaliação ultrapassados, sem incluir avaliação de inflamação e de perda de inserção a longo prazo $^{3}$. Contudo, devemos levar também em consideração que a progressão da doença periodontal é lenta e multifatorial. $O$ estudo longitudinal randomizado controlado ideal é praticamente impossível de ser implementado, anti-ético e muito custoso. Qual seria o endpoint para avaliação da efetividade do fio: perda de inserção em alguns sítios, ou até a perda do dente? Considerando a lenta e imprevisível progressão da doença periodontal, quanto tempo a amostra deveria ser monitorada: 5, 10 ou 15 anos? Talvez muitos indivíduos não apresentarão perda de inserção nem com 20 anos de acompanhamento. 
O estudo de Löe, 19654, avaliou o desenvolvimento de gengivite experimental em 21 dias, após cessar higiene oral. Ao final do estudo, todos os pacientes apresentaram gengivite, com sinais evidentes de inflamação. A escova dental não alcança o espaço interproximal, e a doença periodontal destrutiva e cárie têm potencial de se desenvolver favoravelmente neste nicho retentivo. Portanto, apesar da evidência científica ainda não comprovar a eficácia do uso do fio, este e o uso de escovas interproximais ainda são os métodos confiáveis de higienização interproximal. Enquanto o estudo "ideal e perfeito" para avaliação longitudinal do uso do fio dental não for publicado, os dentistas continuam a recomendar a eleição de um método de limpeza interproximal diariamente para manter a saúde bucal.

\section{REFERENCES}

1. Donn J. Medical benefits of dental floss unproven. Associated Press Report by Jeff Don [Internet]. 2016 [cited 2016 August 2]. Available from: http://bigstory.ap.org/article/ f7e66079d9ba4b4985d7af350619a9e3/ medical-benefits-dental-floss-unproven

2. Sambunjak D1, Nickerson JW, Poklepovic T, Johnson TM, Imai P, Tugwell $P$ et al. Flossing for the management of periodontal diseases and dental caries in adults. Cochrane Database Syst Rev. $2011 ; 7(12)$. doi: 10.1002/14651858.CD008829. pub2

3. American Academy of Periodontology. Flossing in the news - Medial Speaking Points [Internet]. 2016.

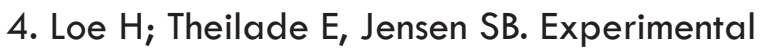
gingivitis in man. J. Periodontol. 1965;36:177-87. doi: 10.1902/jop.1965.36.3.177 